\title{
GAMBARAN AKTIVITAS FISIK DAN KEBUGARAN JASMANI MAHASISWI DI KABUPATEN PURWAKARTA
}

\author{
Ali Akbar ${ }^{1}$, Irwan Haryanto ${ }^{1 *}$, Tomi Herutomo ${ }^{1}$, Naintina Lisnawati ${ }^{2}$ \\ ${ }^{1}$ Sekolah Tinggi Ilmu Kesehatan Holistik \\ ${ }^{2}$ Universitas Diponegoro \\ *Korespondensi: Jl. Veteran No. 272 Ciseureuh Purwakarta, Email: irwanhyt@yahoo.com
}

\begin{abstract}
ABSTRAK
Latar belakang : Kebugaran jasmani mempunyai peran penting bagi mahasiswi untuk menunjang prestasi belajar, mengerjakan tugas, praktikum dan kegiatan organisasi. Dampak kebugaran yang tidak baik dapat menyebabkan menurunnya tingkat konsentrasi pada mahasiswi sehingga dapat menurunkan prestasi belajar. Tujuan dari penelitian ini yaitu untuk mengetahui gambaran aktivitas fisik dan kebugaran jasmani pada mahasiswi di Kabupaten Purwakarta.

Metode : Penelitian ini merupakan jenis penelitian observasional analitik menggunakan rancangan cross sectional. Subjek dalam penelitian ini sebanyak 66 mahasiswi dalam bidang kesehatan di Kabupaten Purwakarta. Aktivitas fisik diukur menggunakan recall aktivitas fisik 1x24 jam dan kebugaran jasmani diukur dengan metode Harvard Step Test. Analisis data yang digunakan yaitu analisis deskriptif, antara lain mean, frekuensi, dan persentase.

Hasil : Sebagian besar subjek (72,7\%) mempunyai tingkat aktivitas fisik ringan, sedangkan 43,9\% dan 34,8\% subjek masing-masing termasuk mempunyai tingkat kebugaran jasmani kurang dan sangat kurang. Subjek dengan aktivitas fisik ringan cenderung mempunyai tingkat kebugaran jasmani kurang.
\end{abstract}

Simpulan : Mahasiswi bidang kesehatan di Kabupaten Purwakarta cenderung mempunyai tingkat aktivitas fisik ringan dan kebugaran jasmani kurang.

Kata kunci: Kebugaran jasmani, aktivitas fisik, mahasiswi

\begin{abstract}
Background : Physical fitness has an important roles for college students, especially for support the learning achievement, work on assignments, learning practices and organizational activities. The impact of lack of physical fitness can decrease the level of concentration of students and it can reduce learning achievement. The purpose of this study was to determine the description of physical activity and physical fitness in female college students in Purwakarta Regency.

Method: This study was an analytic observational study used a cross sectional design. Subjects in this study were 66 female college students with major of health in Purwakarta Regency. Physical activity was measured using 1x24 hour physical activity recall and physical fitness was measured by the Harvard Step Test method. Analysis of the data used descriptive analysis, including mean, frequency and percentage.
\end{abstract}

Result : Most of subjects (72.7\%) had a light level of physical activity, while 43.9\% and 34.8\% of subjects had less and very less physical fitness levels, respectively. Subjects with light physical activity tend to have less physical fitness.

Conclusion : Female health college students in Purwakarta Regency tend to have less physical activity and less physical fitness.

Key words: Physical fitness, physical activity, female college students

\section{PENDAHULUAN}

Kebugaran jasmani adalah gambaran kondisi fisik seseorang untuk melakukan aktivitas sehari-hari, dimana seseorang dapat melakukan tugas atau pekerjaan fisik dan tidak mudah merasa lelah saat melakukan pekerjaan atau tugas tersebut. ${ }^{1}$ Semakin tinggi tingkat kebugaran jasmani seseorang maka semakin baik pula kemampuan fisiknya untuk mengerjakan aktivitas sehari-hari seperti bekerja, belajar, melakukan pekerjaan rumah dan lain-lain. 
Manfaat kebugaran jasmani yang baik yaitu dapat melancarkan aliran darah, memperkuat otot jantung, memperbaiki fleksibilitas otot dan sendi, meningkatkan konsentrasi dan dapat membantu mengendalikan stress. ${ }^{1}$

Badan Centers for Disease Control and Prevention (CDC) melaporkan bahwa dalam beberapa tahun terakhir terjadi penurunan tingkat kebugaran jasmani pada anak dan remaja usia 12 - 15 tahun. Pada tahun 2012, $42,2 \%$ anak dan remaja di Amerika Serikat memiliki tingkat kebugaran cukup atau sedang. Hasil tersebut menurun apabila dibandingkan dengan survei tingkat kebugaran jasmani pada tahun 1999 2004, dengan didapatkan sebesar 52,2\% anak dan remajanya memiliki tingkat kebugaran jasmai yang cukup atau sedang. ${ }^{2}$ Hasil survei dari tim pengembang Sport Development Index (SDI) menyatakan bahwa hampir $80 \%$ masyarakat Indonesia memiliki kebugaran jasmani yang buruk. Rendahnya tingkat kebugaran jasmani tersebut dapat diakibatkan oleh berkembangnya teknologi yang mempengaruhi kebugaran jasmani setiap individu terutama di kalangan anak-anak dan remaja. ${ }^{3}$

Pada hakikatnya terdapat perbedaan antara laki-laki dan perempuan dari segi fisik, baik secara anatomis maupun fisiologis. Secara fisik, laki-laki dewasa ratarata 7 - $10 \%$ lebih besar dari pada perempuan. Perbedaan ukuran itu sangat kecil terlihat pada anak-anak sampai usia pubertas. Kebugaran jasmani pada laki-laki yang lebih tinggi karena pengaruh hormon di dalam otak selama perkembangan janin. Pengaruh hormon testoteron mengakibatkan laki-laki tumbuh lebih tinggi, gelang bahu yang lebih luas, panggul lebih sempit dan tungkai lebih panjang. Sedangkan pengaruh hormon estrogen mengakibatkan perempuan berkembang dengan bahu yang lebih sempit, panggul yang lebih luas relatif terhadap tinggi badannya. Pada perempuan terjadi penimbunan lemak selama masa pubertas, sedangkan pada pria terjadi perkembangan otot. Sehingga perempuan dewasa mempunyai lemak sekitar dua kali lebih besar dari pada laki-laki. ${ }^{4}$ Kebugaran jasmani berkaitan erat dengan aktivitas fisik, tidak terkecuali pada perempuan. Oleh karena itu, tujuan penelitian adalah untuk mengetahui gambaran aktivitas fisik dan kebugaran jasmani mahasiswi di Kabupaten Purwakarta.

\section{METODE PENELITIAN}

Penelitian ini merupakan jenis penelitian observasional analitik menggunakan rancangan cross sectional. Subjek dalam penelitian ini sebanyak 44 mahasiswi dalam bidang kesehatan di Kabupaten Purwakarta. Tingkat aktivitas fisik diukur menggunakan recall aktivitas fisik 1x24 jam, karakteristik subjek diukur menggunakan kuesioner, sedangkan kebugaran jasmani diukur dengan metode Harvard Step Test. Analisis data yang digunakan yaitu analisis deskriptif berupa rerata (mean), frekuensi, dan persentase.

\section{HASIL PENELITIAN}

Subjek dalam penelitian berjumlah 44 mahasiswi di Kabupaten Purwakarta dengan rerata usia 19 tahun, dengan usia terendah adalah 18 tahun dan tertinggi adalah 25 tahun.

Tabel 1. Distribusi Karakeristik Subjek Penelitian

\begin{tabular}{lcc}
\hline \multicolumn{1}{c}{ Variabel } & Mean \pm SD & Min - max \\
\hline Aktivitas Fisik & $1,50 \pm 0,60$ & $0,52-3.21$ \\
Usia & $19,81 \pm 1,72$ & $18-25$ \\
Kebugaran Jasmani & $61,32 \pm 1,44$ & $44,33-132,30$ \\
\hline
\end{tabular}

Berdasarkan Tabel 1, rerata skor aktivitas fisik pada responden adalah $1,50 \pm 0,60$, sedangkan skor kebugaran jasmani adalah $61,32 \pm 1,44$. Jika dilihat dari tingkatan, kategori aktivitas fisik dan kebugaran jasmani subjek dapat diklasifikasikan sebagai berikut : 


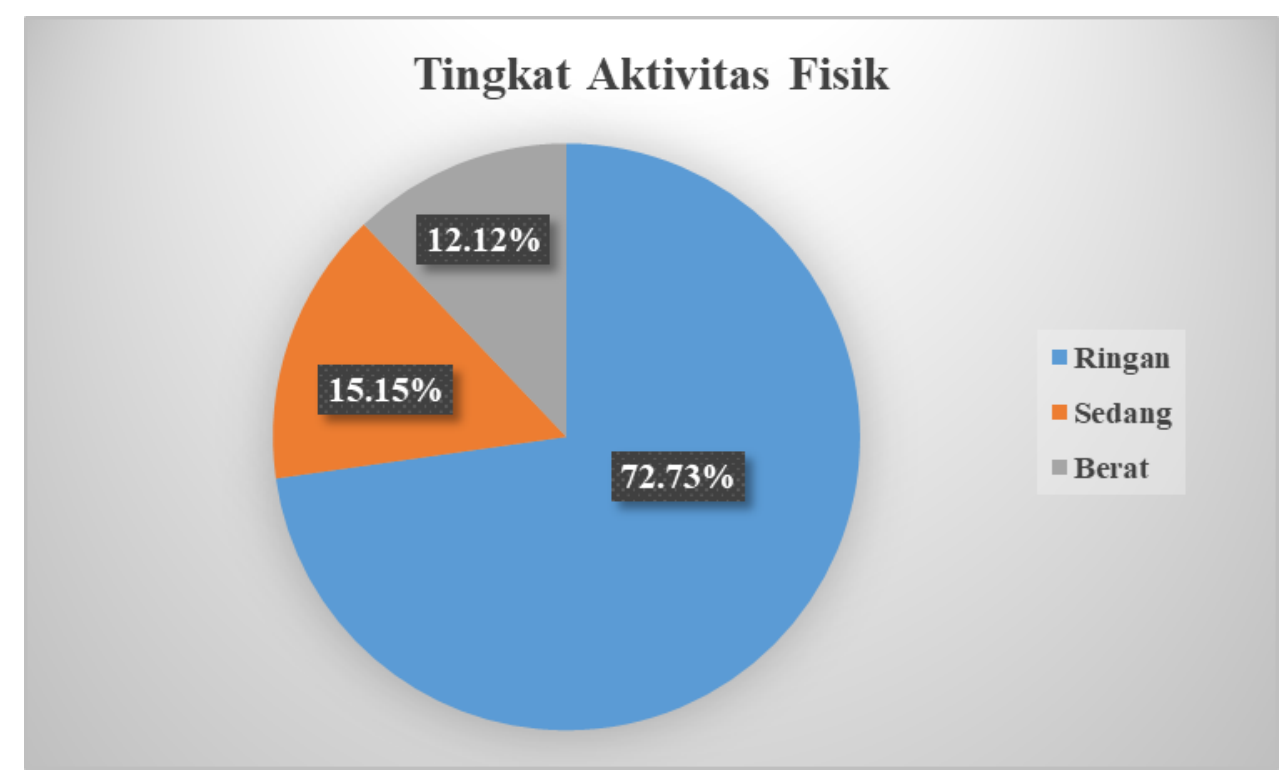

Gambar 1. Tingkat Aktivitas Fisik Subjek Penelitian

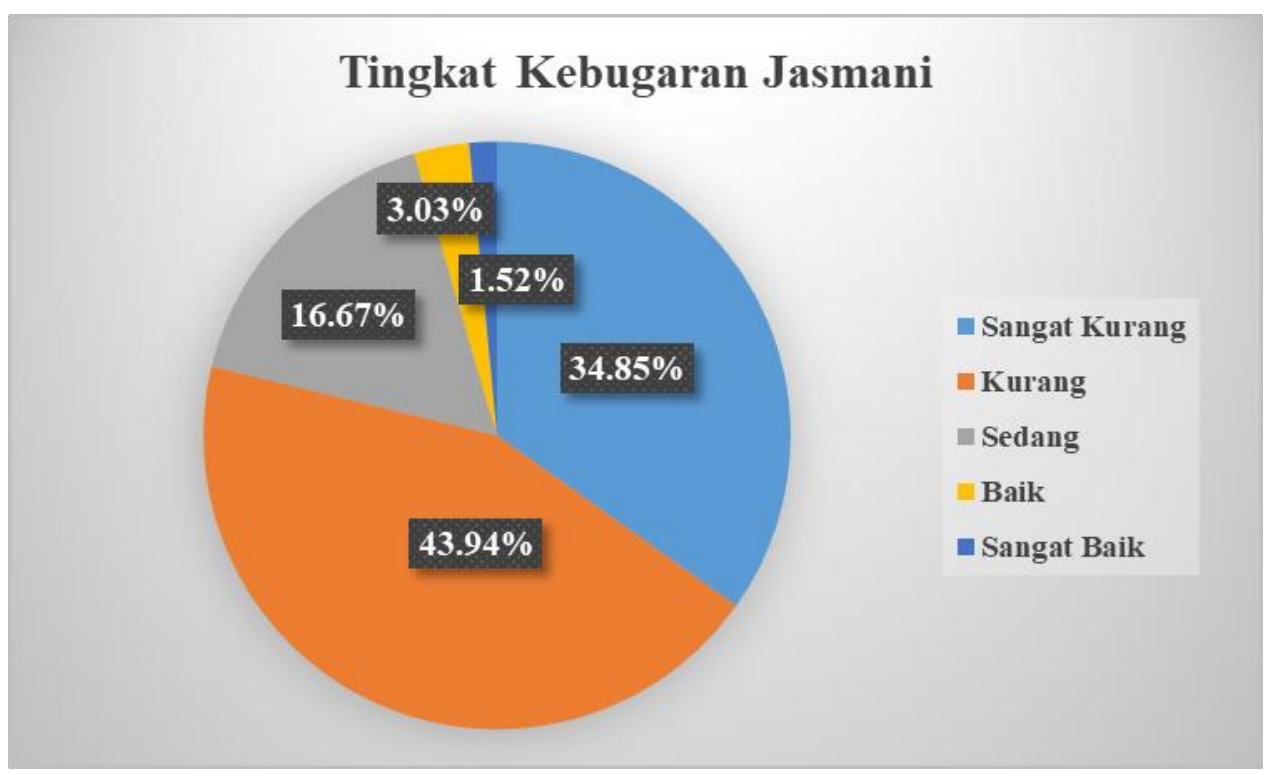

Gambar 2. Tingkat Kebugaran Jasmani Subjek Penelitian

Tingkat aktivitas fisik diklasifikan menjadi 3 (tiga) kategori, yaitu ringan, sedang, dan berat. Sedangkan, tingkat kebugaran jasmani diklasifikasikan menjadi 5 (lima) kategori, yaitu sangat kurang, kurang, sedang, baik, dan sangat baik. Berdasarkan hasil analisis, sebagian besar subjek mempunyai tingkat aktivitas fisik ringan $(72,73 \%)$, sementara untuk kategori sedang dan berat masing-masing adalah $15,15 \%$ dan 12,12\%. Selain itu, untuk tingkat kebugaran jasmani, sebagian besar subjek tergolong dalam kategori kurang (43,94\%) dan sangat kurang (34,85\%). Sedangkan untuk subjek penelitian yang tergolong dalam kategori kebugaran jasmani sedang, baik, dan sangat baik masing-masing adalah $16,67 \% ; 3,03 \%$, dan $1,52 \%$.

\section{PEMBAHASAN}

Kebugaran jasmani merupakan kebutuhan dasar bagi seseorang untuk melakukan aktivitas fisik secara berulangulang dalam waktu yang relatif lama tanpa menimbulkan kelelahan yang berarti. Jika seseorang mempunyai kebugaran jasmani yang baik maka diharapkan akan mampu bekerja dengan produktif dan efisien, tidak terserang penyakit, belajar lebih semangat 
serta dapat berprestasi secara optimal. Sebuah penelitian di Kabupaten Sleman pada tahun 2012, menunjukkan bahwa $12 \%$ mahasiswa masuk dalam kategori kurang sekali, 26\% mahasiswa masuk kategori tingkat kebugaran kurang dan 31\% masuk kategori sedang. Kebugaran jasmani dapat terganggu akibat pola hidup dan kebiasaan yang kurang baik, misalnya merokok, penyalahgunaan obat atau zat yang berbahaya, pola makan yang tidak teratur, tidur yang tidak teratur, kebiasaan itu sudah menjadi kebiasaan masyarakat umum. ${ }^{5}$

Analisis data diperoleh bahwa sebagian besar subjek (43,94\%) mempunyai tingkat kebugaran jasmani kurang dengan rerata skor kebugaran jasmani sebesar $61,32 \pm 1,44$. Sedangkan, subjek penelitian yang tergolong mempunyai kebugaran jasmani baik sebesar 3,03\%. Fungsi kebugaran jasmani yaitu untuk meningkatkan sistem sirkulasi darah, sistem saraf, dan fungsi jantung, melatih persendian agar tidak kaku serta dapat meningkatkan konsentrasi pada saat belajar. Sedangkan manfaat kebugaran jasmani adalah kemampuan dan ketahanan tubuh untuk melakukan kerja dan beraktivitas tanpa mengalami kelelahan yang berlebihan atau signifikan. Manfaat kebugaran jasmani secara umum adalah untuk meningkatkan kemampuan tubuh agar tidak mudah lelah dalam melakukan suatu aktivitas.

Aktivitas fisik subjek penelitian sebagian besar $(72,73 \%)$ tergolong dalam kategori ringan dengan rerata skor aktivitas fisik sebesar 1,50 $\pm 0,60$. Aktivitas fisik dapat mempengaruhi tingkat kebugaran jasmani. Seseorang dengan aktivitas fisik yang tinggi akan jauh lebih bugar dibandingkan dengan seseorang dengan aktivitas fisik yang rendah. Semakin tinggi aktivitas fisik yang dilakukan seseorang mempengaruhi semakin meningkatnya kebugaran jasmani seseorang. 6 Aktivitas fisik adalah pergerakan tubuh yang dihasilkan oleh otot rangka yang menghasilkan pengeluaran energi seperti berjalan atau berlari, olahraga, dan aktivitas waktu luang seperti membaca, dan membersihkan rumah. Latihan aerobik dapat meningkatkan nilai VO2max dikarenakan saat melakukan latihan tersebut distribusi oksigen ke otot meningkat sehingga memberi kemampuan untuk melakukan aktivitas olahraga dengan waktu yang lebih lama dan konsumsi V02max menjadi lebih besar. Hasil penelitian pada siswa SMP di Banjarmasin menunjukan adanya hubungan yang signifikan antara V02maks dengan aktivitas fisik. ${ }^{7}$ Laki-laki mempunyai darah yang kurang lebih satu liter lebih banyak dari pada perempuan. Selain itu dimensi jantung pada laki-laki lebih besar sehingga volume sedenyut lebih besar, volume paru-paru laki-laki lebih besar $10 \%$ dari pada perempuan. ${ }^{8}$

\section{SIMPULAN}

Aktivitas fisik dan kebugaran jasmani mahasiswi kelompok bidang kesehatan di Kabupaten Purwakarta sebagian besar tergolong ringan dan kurang. Oleh karena itu, perlu adanya kegiatan terkait peningkatan kebugaran jasmani mahasiswi di lingkungan kampus, agar konsentrasi belajar mahasiswi meningkat dan dapat mencapai prestasi yang optimal.

\section{DAFTAR PUSTAKA}

1. Kemenkes RI. Pedoman Pembinaan Kebugaran Jasmani Peserta Didik Melalui Upaya Kesehatan Sekolah. Direktorat Bina Kesehatan Kerja Dan Olahraga Ditjen Bina Gizi Dan Kesehatan Ibu Dan Anak. 2013.

2. CDC. Cardiorespiratory Fitnes Levels Among U.S Youth Aged 12-15. United States, 1999-2004 an 2012. NCHS Data Brief 2014.

3. Kardiawan IKH. Pengaruh Pelatihan Olahraga Tradisional Bali terhadap Kebugaran Jasmani Siswa Sekolah Dasar. Jilid 46 Nomor 2.Bali: UPG. 2013.

4. Nopembri S. Menstruasi Dan Osteoporosis Faktor Yang Mempengaruhi Aktivitas Jasmani Wanita. Jurusan Pendidikan Olahraga FIK UNY. 2007.

5. Prabowo, Rizka F D. Tingkat Kebugaran Jasmani Siswa Sekolah Sepaktakraw Usia 
10-12 Tahun Di Kabupaten Sleman. Fakultas Ilmu Keolahragaan. UNY. 2012.

6. Ringgo, Alfarizi., Wahyu, karhiwikarta., Dessy, hermawan. Faktor-faktor yang mempengaruhi kebugaran jasmani mahasiswa kedokteran. Fakultas Kesehatan Masyarakat Universitas Malahayati, Vol 2. 2013.
7. Sulistiono, Agus Amin. Prediksi Aktifitas Fisik Sehari-hari, Umur, Tinggi, Berat Badan dan Jenis Kelamin Terhadap kebugaran Jasmani. BalitbangKemdikbud. 2014.

8. Soni, Nopembri. Menstruasi Dan Osteoporosis Faktor Yang Mempengaruhi Aktivitas Jasmani Wanita. Jurusan Pendidikan Olahraga FIK UNY. 2007. 